\title{
IMIGRAÇÃO E DINÂMICA FAMILIAR: UMA REVISÃO TEÓRICA
}

\author{
IMMIGRATION AND FAMILY DYNAMICS: A THEORETICAL REVIEW \\ INMIGRACIÓN Y DINÁMICA FAMILIAR: UNA REVISIÓN TEÓRICA
}

\author{
Ana Paula Sesti Becker \\ Lucienne Martins Borges ${ }^{* *}$ \\ Maria Aparecida Crepaldi**
}

\begin{abstract}
RESUMO
No panorama contemporâneo, são constantes as expansões das fronteiras internacionais, as quais desencadeiam um impacto decisivo na vida dos indivíduos e nos contextos socioculturais, especialmente no universo relacional da família. Assim, objetiva-se analisar a produção científica entre o processo migratório e a dinâmica familiar de imigrantes. Realizouse o levantamento bibliográfico a partir de buscas em bancos de dados nacionais e internacionais, mediante descritores preestabelecidos. A análise dos documentos foi delimitada entre o período de 1980 a 2013. Compreenderam-se produções de artigos científicos, teses e dissertaçôes. Os aspectos metodológicos e semânticos foram reunidos em cinco categorias de análise. Os resultados apontam lacunas existentes na produção científica relacionada estritamente ao tema de migração e dinâmica familiar. Em seguida, destacam o processo de adaptação cultural que as famílias vivenciam ao imigrarem. Discute-se a ênfase conferida às dimensóes psicossociais que norteiam o ciclo vital da família a partir do processo migratório.
\end{abstract}

Palavras-chave: Migração. Psicologia intercultural. Família.

\section{ABSTRACT}

In the contemporary landscape, the expansion of international borders are constant, which initiates a decisive impact on the lives of individuals and socio-cultural contexts, especially in the family relational universe. Thus, the objective is to review scientific literature that addresses the relationship between the migratory process and family dynamics of immigrants. We conducted a bibliographic search on national and international databases, using pre-established descriptors. The analysis of documents was delimited between the period 1980 to 2013. From the understanding of the production

\footnotetext{
Texto recebido em 3 de janeiro de 2015 e aprovado para publicação em 17 de agosto de 2015.

Mestranda no Programa de Pós-Graduação em Psicologia, Universidade Federal de Santa Catarina (UFSC). Florianópolis-SC, Brasil.E-mail: anapaulasbc@hotmail.com.

** Doutora em Psicologia, docente no Programa de Pós-Graduação em Psicologia da UFSC. E-mail: lucienne.borges@ufsc.br.

"** Doutora em Psicologia, docente no Programa de Pós-Graduação em Psicologia da UFSC. E-mail: maria.crepaldi@gmail.com.
} 
of scientific papers, theses and dissertations. The methodological and semantic aspects were divided into five categories of analysis. The results point to gaps at the related scientific production strictly to the migration issue and family dynamics, now highlight the process of cultural adaptation that families experience when immigrating. It discusses the emphasis on psychosocial dimensions that guide the life cycle of the family from the migration process.

Keywords: Migration. Cross-cultural. Family.

\section{RESUMEN}

En el panorama contemporáneo, son constantes las expansiones de las fronteras internacionales, lo que provoca un impacto decisivo en la vida de los individuos y en los contextos socio-culturales, sobre todo en el universo relacional de la familia. Por lo tanto, se busca analizar la literatura científica que se ocupa de la relación entre el proceso migratorio y la dinámica familiar de los inmigrantes de la familia. Se realizó una búsqueda bibliográfica en los bancos de datos nacionales e internacionales, entre el período de 1980 a 2013. Se contemplaron las producciones de trabajos científicos, tesis y disertaciones. Los aspectos metodológicos y semánticos se dividieron en cinco categorías de análisis. Los resultados muestran lagunas en la producción científica relacionada estrictamente con el tema de la migración y la dinámica familiar. A continuación, destaca el proceso de adaptación cultural que las familias experimentan cuando emigran. Se discute el énfasis concedido a las dimensiones psicosociales que guían el ciclo vital de la familia a partir del proceso de migración.

Palabras clave: Migración. Psicología intercultural. Familia.

\section{INTRODUÇÃO}

N

o panorama contemporâneo, são notórias as constantes mobilidades humanas que resultam em mudanças significativas na vida dos indivíduos. Isso se explica, em grande parte, pelas aceleradas expansões territoriais das fronteiras nacionais e internacionais, pelo aumento maciço da tecnologia e pelo incremento da globalização. Esse, portanto, é um processo com base no qual se reestruturam as quatro formas de poder (econômicas, políticas, culturais e simbólicas) que permeiam a conjuntura dos fluxos migratórios e do cenário singular dos sujeitos (Dantas, 2012).

A Psicologia Intercultural possibilita uma visão integradora das dimensões psicossociais, compreendendo o desenvolvimento humano decorrente de uma 
relação dialética entre o sujeito e os contextos socioculturais estabelecidos. Nessa perspectiva, o enfoque intercultural se prima por descrever e compreender a influência dos fatores culturais no desenvolvimento, nos comportamentos e no sofrimento psíquico dos migrantes (Sarriera, Pizzinato, \& Meneses, 2005).

Conforme Martins-Borges (2013), torna-se preponderante considerar o universo simbólico no qual o sujeito está inserido, uma vez que o mundo interno (mundo psíquico) e o mundo externo (cultura) podem se comunicar, encontrando mutuamente significados, já que têm uma mesma linguagem. Acerca disso, a autora entende como migrante aquele sujeito que se encontra fora da zona geográfica cultural na qual se constituiu como sujeito, de modo que a comunicação entre o mundo externo e o mundo interno do migrante se encontra, pelo menos temporariamente, abalada, o que pode repercutir num estado de vulnerabilidade psíquica.

Fundamentando-se em tais considerações, um dos focos prementes de estudos e intervenções na área se pautam na análise da adaptação psicológica dos indivíduos e grupos quando mudam de cultura. Tal demanda permite-nos um olhar atento aos processos de adaptação como bem propõem autores clássicos da Psicologia intercultural. Não obstante, é fundamental conceber as relações que se estabelecem quanto às construções identitárias de cunho nacional e étnico dos indivíduos (Dantas, Ueno, Leifert, \& Suguiura, 2010). Nesse sentido, salientase, ainda, a importância de verificar a presença ou ausência das redes sociais e de apoio que os migrantes dispóem quando chegam a um novo contexto sociocultural, bem como as dimensões estabelecidas da imigração no ciclo de vida familiar destes.

No que se reporta ao papel das redes sociais nos processos migratórios, Sluzki (1997) argumenta que estas podem promover o bem-estar e acolhimento às famílias imigrantes consoantes ao processo de adaptação em um novo contexto cultural. Por conseguinte, concebe-se como rede social a soma de todas as relações que um sujeito identifica como significativas e que, de certa, forma contribuirão para a construção da identidade e de sua autoimagem. Desse modo, as redes incluem os vínculos que compreendem a vida da pessoa, envolvendo relaçóes familiares, de amizade, trabalho ou estudo, bem como sua inserção comunitária e com as práticas sociais.

Diante disso, é importante considerar que, não somente no âmbito singular dos sujeitos, mas na dimensão grupal e, desse modo, familiar dos migrantes, são diversos os fenômenos decorrentes das mobilidades que implicam a reelaboração do universo simbólico de seus membros. Nesse quesito, convém ressaltar o fenômeno de aculturação que, de acordo com Berry (2004), designa o processo 
de mudança que decorre do contato contínuo com outra cultura. Isso implica a reflexão das transformações em todas as situações de contato entre os grupos não dominantes (como imigrantes, refugiados, povos indígenas) e a população majoritária. Para o autor, existem estratégias adotadas entre esses grupos que variam desde a manutenção da cultura de origem e da identidade étnica dos imigrantes até a acomodação mútua ou restriçôes que a cultura dominante pode exercer no processo.

Dessa forma, a imigração implica a complexidade de relações que se estendem tanto na dimensão cultural do país de acolhimento quanto no âmbito psicossocial do indivíduo, em suas redes sociais e no ciclo vital familiar que se encontra. Neste último aspecto, destacam-se os impactos da imigração na dinâmica familiar. Minuchin (1982) esclarece que a dinâmica familiar é, portanto, o conjunto de formas de funcionamento familiar, relações hierárquicas e de poder que se estabelecem entre os membros.

Entende-se que o desenvolvimento da família perpassa o ciclo vital de seus membros, constituído por um conjunto de estágios sucessivos no processo de vida do ser humano. Tal concepção nos remete ao fato de que cada estágio tem tarefas específicas a serem cumpridas tanto pelo indivíduo quanto pelo seu respectivo sistema familiar, desencadeando um processo de transição para uma nova etapa do ciclo (Cerveny, 2002). Tais transições podem ser consideradas normativas quando são previsíveis e não normativas quando não esperadas, neste último aspecto, enquadra-se a migração (Carter \& McGoldrick, 1995).

É oportuno destacar que o fenômeno migratório pode ser dividido entre migrações internas e internacionais. Neste estudo, serão revisadas pesquisas que tratem da imigração de famílias quando estas transpõem os limites da federação. Nesse sentido, Queiroz (2008) reflete que a acelerada quebra das fronteiras internacionais teve um impacto decisivo nos contextos socioculturais, influenciando preponderantemente o universo relacional da família, o que precisa ser considerado por meio da construção de políticas públicas de suporte social e acolhimento nos contextos migratórios.

Levando em consideração tais pressupostos, adotou-se como fundamento teórico deste estudo a Psicologia intercultural e o pensamento sistêmico para compreender a complexidade do fenômeno migratório, bem como as relaçóes estabelecidas na dinâmica familiar dos sujeitos. Assim, este artigo tem como objetivo analisar a produção científica nacional e internacional que contempla a relação entre o processo migratório e a dinâmica familiar de imigrantes. 


\section{MÉTODO}

A revisão de literatura compreendeu as seguintes fases de elaboração:

a) levantamento da produção científica em banco de dados;

b) leitura dos resumos e seleção dos artigos vinculados ao objetivo deste estudo;

c) leitura das obras obtidas;

d) definição das categorias de análise; e, por fim,

e) análise e articulação dos resultados obtidos nos trabalhos avaliados;

Conforme modelo proposto pela revisão bibliográfica de Schmidt, Crepaldi, Vieira, e Moré (2011). O levantamento de dados delineou-se com base em buscas realizadas em plataformas de pesquisa nacionais e internacionais. Os campos utilizados nacionalmente foram a Biblioteca Virtual em Saúde - Psicologia Brasil (BVS-Psi), Lilacs, Scielo Brasil e Coordenação de Aperfeiçoamento de Pessoal de Nível Superior (Capes), sendo estas de acesso livre. A base de dados internacional consultada foi a interface Ebsco - Host, de acesso restrito, sendo selecionada a base de dados Academic Search Complete.

Inicialmente se optou por selecionar os descritores de busca na seção de terminologia em Psicologia da BVS-Psi. O termo pré-selecionado para o estudo foi "migração". Desse modo, o sítio apontou sete sugestôes de busca: "refugiados", "processos sociais", "migração humana", "migração animal", "exilados", “imigração" e "comportamento migratório" (animal). Tendo em vista que o ensejo da pesquisa se pautou por investigar o fenômeno migratório internacional, delineou-se como escolha o descritor "imigração". Posteriormente, recorreu-se ao operador "AND" para incluir ao descritor selecionado o termo "família", a fim de se encontrarem as associaçóes entre o processo migratório e a dinâmica familiar de imigrantes. Desse modo, as estratégias de busca foram as seguintes:

a) "imigração and família”;

b) "imigration and family" e

c) “inmigración y familia”. Consideraram-se, portanto, as versōes entre os achados nos idiomas português, inglês e espanhol. 
O período entre as buscas selecionadas foi entre os anos de 1980 a 2013. Os estudos adotados para a análise contemplaram artigos científicos, teses e dissertações em níveis nacional e internacional. Cabe salientar que foram selecionadas para o estudo as referências disponíveis no que condiz ao resumo e, ou, ao texto na íntegra.

Posteriormente, iniciou-se o processo de exclusão por meio de critérios como: trabalhos duplicados (disponibilizados em mais de um banco de dados, como também repetidos no mesmo banco); ou aqueles estudos que não abarcavam diretamente a temática proposta, por exemplo: estudos de aculturação e saúde mental que dimensionavam somente o ponto de vista do sujeito e não focavam o sistema familiar ou ainda relatos empíricos e históricos que retrataram a descendência de famílias imigrantes, como nos idos da colonização brasileira. Foram excluídas, ainda, referências que não apresentaram resumo.

Pelas buscas realizadas nas plataformas citadas previamente, foram encontrados 212 trabalhos, entre artigos publicados em periódicos científicos, teses e dissertações. Desses resultados, encontraram-se 152 nas plataformas nacionais, sendo 34 na BVS-Psi (22 no Lilacs; 12 no Scielo) e 118 na Capes. $\mathrm{Na}$ plataforma internacional Ebsco-Host, encontraram-se 60 resultados no Academic Search Complete. Da exclusão da duplicidade de trabalhos e obras sem o resumo disponível, restaram 200 trabalhos. Destes, somente em três não foi possível consultar o texto na íntegra. Por fim, foram lidos 200 resumos nacionais e internacionais.

Pela leitura dos resumos, 24 estudos estavam diretamente relacionados à temática que a pesquisa apresentou como finalidade. Destes, 23 referiram-se a artigos publicados em periódicos e apenas um se remetia ao resumo de uma tese. Somente duas obras não puderam ser consultadas na íntegra, pois se tratavam de um artigo não gratuito, inviabilizando o acesso ao texto completo, e o outro resumo, referente à tese de doutorado, não estava acessível por meio da internet. Os demais 22 artigos foram lidos na íntegra.

$\mathrm{Na}$ penúltima etapa do processo bibliográfico, definiram-se categorias de análise metodológicas, a fim de se avaliar cada trabalho: enfoque do estudo; tipo do estudo (longitudinal/transversal); método (experimentação, levantamento de dados e combinação entre dois ou mais métodos); técnicas utilizadas (entrevistas, observações, questionários); análise de dados quantitativa / qualitativa / multimétodo); características sociodemográficas do estudo (participantes e faixa etária destes); periódicos e ano de publicação dos artigos. Por fim, estabeleceramse categorias semânticas com base nos resultados que mais emergiram conforme as temáticas contempladas nos artigos: 

a) "aculturação familiar";
b) "ausência dos membros familiares pela imigração";
c) “juventude e imigração familiar";
d) "manutenção das tradições culturais e familiares de origem"; e
e) “imigração e projeto de vida familiar”.

\section{RESULTADOS}

Verificou-se que, dos 24 estudos alinhados à temática, 21 foram publicados a partir dos anos 2000, enquanto que apenas 1 foi publicado no início da década de 1980 e, posteriormente, 2 no final da década de 1990. Salienta-se que um dos trabalhos pesquisados se identifica como obra de dissertação, de modo que não constou da análise realizada acerca dos periódicos consultados.

No que concerne aos periódicos cujos trabalhos foram publicados, constata-se que a revista Journal of Ethnic and Migration Studies obteve maiores ocorrências de publicaçõos entre as demais que emergiram, obtendo 5 artigos no período pesquisado. Em seguida, apontam-se os periódicos Journal of Youth Adolescence, Family Process e Horizontes Antropológicos, com 2 publicaçôes entre os anos de 2000 a 2012. Os demais estudos distribuíram-se igualmente em outros 12 periódicos (sendo uma publicação por periódico), conforme se pode ver na tabela 1 . Em relação às revistas citadas, observa-se que somente 2 coadunam-se à área da Psicologia, enquanto que 10 contemplam o campo multidisciplinar das Ciências Humanas e da Saúde. As demais compõem diferentes áreas do conhecimento, como Antropologia, História, Literatura e Sociologia.

Tabela 1. Nome dos periódicos, ano de publicação e frequência de artigos publicados acerca da relação entre o fenômeno migratório e a dinâmica familiar

\begin{tabular}{l|c|c}
\hline \multicolumn{1}{c|}{ Periódico } & Ano de publicação & Frequência (n) \\
\hline \multirow{3}{*}{ Journal of Ethnic and Migration } & 2011 & 2 \\
Studies & 2009 & 1 \\
& 2008 & 1 \\
\hline \multirow{2}{*}{ Journal of Youth Adolescence } & 2007 & 1 \\
\hline \multirow{2}{*}{ Family Process } & 2006 & 1 \\
& 2008 & 1 \\
\hline
\end{tabular}




\begin{tabular}{l|c|c}
\hline Horizontes Antropológicos & 2000 & 2 \\
\hline $\begin{array}{l}\text { Revista Latinoamericana de Ciencias } \\
\text { Sociales, Niñez y Juventud }\end{array}$ & 2012 & 1 \\
\hline Literacy & 2011 & 1 \\
\hline Migraciones Internacionales & 2010 & 1 \\
\hline Cultura del Cuidado Enfermería & 2009 & 1 \\
\hline Journal of Adolescence & 2007 & 1 \\
\hline Pensando Famílias & 2007 & 1 \\
\hline Estudos de Psicologia & 2005 & 1 \\
\hline Columbia University School of Social & 2005 & 1 \\
\hline Work & 2002 & 1 \\
\hline Social \& Cultural Geography & 1997 & 1 \\
\hline Revista Brasileira de História & 1997 & 1 \\
\hline Sociologias: Problemas e Práticas & 1982 & \\
\hline Acta Médica Colombiana & 23 & 1 \\
\hline TOTAL & & \\
\hline
\end{tabular}

Fonte: elaborado pelas autoras.

No que se refere às características sociodemográficas da amostra, identificou-se que, na maior parte dos estudos (12), foram pesquisados os membros familiares, como a mãe, o pai, os filhos, ou seja, a família. Em 6 pesquisas, participaram jovens imigrantes e, ou, que tiveram algum familiar emigrado. Somente 1 estudo coletou dados com participantes homens e 3 estudos com participantes mulheres, sendo estas imigrantes. Restaram apenas 2 omissóes sobre esse quesito, haja vista que um estudo se tratava de um ensaio teórico, enquanto o outro não constou o detalhamento dos participantes no resumo; considerando que tal periódico não tem acesso gratuito ao texto na íntegra, este não pôde ser consultado.

Em relação à idade dos participantes, nos estudos que se pesquisou a família, a faixa etária variou entre 22 a 81 anos; todavia, em 11 estudos, os autores não apontaram a idade dos membros familiares entrevistados. Quanto à faixa etária dos jovens pesquisados, esta variou entre 12 a 26 anos. O estudo não mencionou a idade dos homens pesquisados, enquanto, entre as mulheres pesquisadas, a idade variou entre 20 a 84 anos de idade.

Quanto aos aspectos metodológicos dos estudos analisados, a prevalência no que se refere ao enfoque de estudo delimitou-se como pesquisa-empírica, totalizando 14 pesquisas. Verificaram-se, ainda, 3 estudos com enfoque etnográfico, bem como outros nas seguintes delimitações: documental, ensaio teórico, relato de experiência e estudo de caso, conforme se pode observar na tabela 2. No que tange ao tipo de estudo, apontaram-se 6 trabalhos com vertente longitudinal, 
enquanto, em 18 estudos, omitiu-se o esclarecimento de tal critério. A análise de dados foi qualitativa na maioria dos trabalhos avaliados.

Na seção método, a prevalência se deu no levantamento de dados, seguidamente da combinação entre levantamento de dados e observação. As técnicas mais utilizadas foram a entrevista, seguido dos questionários, observação e das combinações entre entrevista/grupo focal, entrevista/mapa de redes, entrevista/ escala, questionário/escala e observação/entrevista. Cabe salientar que 2 estudos recorreram aos registros de dados para compor sua análise. Estes se basearam em registros escolares bem como de certidão de casamento, batizado e óbito dos sujeitos-alvo da pesquisa.

As escalas usadas na análise dos estudos foram respectivamente: Adolescent Family Process Measure (AFP) (Vazsonyi, Castillo, \& Huang, 2006); Rosenberg's Self-Estee Scale (Rosenberg, 1965); The Satisfaction with Life Scale (Diener, Emmons, Larsen, \& Griffin, 1985); e The Social Support Network Scale for Adolescents (Adaptado por Antonucci \& Israel, 1986). A primeira foi utilizada no estudo de Vazsonyi, Castillo \& Huang (2006). Tal instrumento tem por finalidade avaliar a proximidade parental, o suporte, monitoramento, comunicação e aprovação dos colegas que os adolescentes indicavam ter. Já as escalas subsequentes foram empregadas na pesquisa de Aksel, Giin, Irmak, \& Cengelci (2007), com o intuito de verificar a autossatisfação, o bem-estar subjetivo bem como a rede de apoio social ao adolescente.

Tabela 2. Aspectos metodológicos dos periódicos revisados

\begin{tabular}{l|c}
\hline \multicolumn{1}{c|}{ Enfoque do estudo } & Frequência (N) \\
\hline Empírico-pesquisa & 14 \\
\hline Etnográfico & 3 \\
\hline Documental & 1 \\
\hline Ensaio teórico & 1 \\
\hline Relato de experiência & 1 \\
\hline Estudo de caso & 1 \\
\hline Omissões & 3 \\
\hline TOTAL & 24 \\
\hline
\end{tabular}




\begin{tabular}{|c|c|}
\hline Tipo de estudo & Frequência (N) \\
\hline Longitudinal & 6 \\
\hline Omissões & 18 \\
\hline TOTAL & 24 \\
\hline Método & Frequência (N) \\
\hline Levantamento de dados & 15 \\
\hline Levantamento de dados/observação & 4 \\
\hline Omissões & 5 \\
\hline TOTAL & 24 \\
\hline Técnica & Frequência ( $N$ ) \\
\hline Entrevistas & 8 \\
\hline Entrevistas/grupo focal & 1 \\
\hline Entrevista/genograma & 1 \\
\hline Entrevistas/escala & 1 \\
\hline Entrevista/Mapa de redes & 1 \\
\hline Questionários & 2 \\
\hline Questionários/escalas & 1 \\
\hline Observação/entrevista & 2 \\
\hline Observação/entrevista/questionário & 1 \\
\hline Observação/entrevista/registro de dados & 1 \\
\hline Registros de dados & 1 \\
\hline Omissões & 4 \\
\hline TOTAL & 24 \\
\hline Análise de dados & Frequência (N) \\
\hline Qualitativo & 14 \\
\hline Quantitativo & 2 \\
\hline Multimétodo & 1 \\
\hline Omissões & 7 \\
\hline TOTAL & 24 \\
\hline
\end{tabular}

Fonte: elaborado pelas autoras. 
Conforme a leitura e análise do conteúdo dos artigos, este foi agrupado em categorias semânticas. Os seguintes temas foram encontrados:

a) adaptação familiar ao novo contexto cultural;

b) ausência de familiares;

c) juventude e imigração familiar;

d) manutenção das tradições culturais e familiares de origem; e

e) imigração e projeto de vida familiar. Serão discutidas, a seguir, cada uma dessas categorias.

\subsection{Adaptação familiar ao novo contexto cultural}

Entre as pesquisas analisadas, 8 tiveram como objeto de estudo os aspectos psicossociais decorrentes do fenômeno migratório de famílias imigrantes. Destas, somente 2 corresponderam à imigração no Brasil, tratando-se de estudos nacionais (Machado, 1997; Sarriera et al., 2005); enquanto os demais foram estudos internacionais (Deepak, 2005; Engebrigtsen, 2007; Hope, 2011; Morrison \& James, 2009; Ryan, Sales, Tilki, \& Siara, 2009; Waters, 2011).

Esses estudos contemplaram as principais dificuldades encontradas pelas famílias migrantes no decorrer do processo de mudança a partir do contato contínuo com outra cultura. Diante disso, no estudo de Deepak (2005), a autora pondera que, se não forem consideradas as diferenças de comportamento, hábitos e modos de relacionamento entre culturas divergentes, pode-se dar vazão ao estresse e conflitos no sistema familiar. Nesta pesquisa, emergiram questóes concernentes ao choque cultural, como diferentes normas e regras de hierarquia nos relacionamentos bem como diferentes papéis que são esperados pelos cônjuges e filhos na sociedade majoritária, em contraste com o contexto de origem. Tais achados podem implicar o casamento e a educação dos filhos dos imigrantes. Resultados semelhantes constaram dos estudos de Morrison e James (2009); Engebrigtsen (2007); Ryan, Sales, Tilki, \& Siara (2009); e Machado (1997).

Ainda no que contempla a dimensão de aculturação na vivência das famílias imigrantes, no estudo de White, Laoire, Tyrrell, \& Méndez (2011), emergiram reflexões acerca do desenvolvimento infantil diante do processo migratório no sistema familiar. De acordo com os autores, recentes estudos têm se pautado sobre a participação dos filhos, especialmente crianças, no processo decisório da migração familiar. Os resultados dessas pesquisas sugerem a importância de 
dar voz às crianças e promover o desenvolvimento comunicacional entre pais e filhos como fator contributivo de adaptação na dinâmica familiar diante das mobilidades a um novo contexto sociocultural.

Assim como as repercussões que o núcleo familiar vivencia no casamento e na educação dos filhos mediante o fenômeno migratório, constatou-se também a ocorrência do impacto na saúde mental das famílias imigrantes. Os achados de Vazsonyi et al. (2006) identificaram a proporção de comportamentos internalizados e externalizados entre filhos de imigrantes jovens e jovens nativos da Suíça. Verificou-se a maior ocorrência de comportamentos internalizados, como a depressão e a ansiedade, em jovens imigrantes e a implicância disso na dinâmica familiar.

Não obstante, outras pesquisas também evocaram a dimensão das redes de apoio social, como promotoras de bem-estar e acolhimento aos imigrantes no processo de aculturação das famílias pesquisadas (Bagno, 2007; Engebrigtsen, 2007; Ryan et al., 2009; Sarriera et al., 2005).

\subsection{Ausência dos familiares}

Três estudos tiveram como finalidade problematizar as repercussōes da imigração para os membros familiares que não emigram, entre estes se citam os filhos, os esposos e pais, bem como demais familiares que sofreram o impacto da ausência de seus parentes e pessoas significativas. Tais resultados podem ser encontrados nas pesquisas de Soto (2012), Mercer (2012), Waters (2002) e Ximena (2005).

O imaginário construído pelos filhos de pais emigrantes, concernentes à experiência das ausências, remete ao estudo de Soto (2012) acerca do descontentamento quanto ao processo decisório da emigração e conflitos comunicacionais, uma vez que a falta de esclarecimentos por parte dos pais podem repercutir sentimentos de abandono e incompreensão na percepção dos jovens. Dados semelhantes foram encontrados na tese de Ximena (2005), a respeito de adolescentes filhos de pais emigrantes, os quais apontaram uma significativa prevalência de sintomas depressivos no curso do desenvolvimento juvenil, bem como emergiram vivências de disfuncionalidade familiar, permeada pela falta de suporte emocional destes adolescentes que não emigraram.

Além do impacto no subsistema parental dos estudos citados, os resultados encontrados por Waters (2002) permitem uma reflexão acerca das repercussões enfrentadas no casamento pelas famílias imigrantes de Hong Kong e Taiwan. Tal cenário vislumbra a realidade de esposas e seus filhos que imigraram para 
Vancouver, Sydney e Auckland, de modo que os esposos permaneceram na Ásia, ambos cooperando para melhores condições de vida da família. Os resultados obtidos refletem o sentimento de sofrimento pelo afastamento entre cônjuges, pais e filhos. Não obstante, foi recorrente a menção aos conflitos conjugais devido ao afastamento bem como as barreiras comunicacionais entre os membros familiares.

Constatou-se, ainda, na pesquisa de Mercer (2012), a dimensão simbólica da ausência dos membros familiares como de luto e perda. Os resultados obtidos enfatizam a necessidade da terapia familiar para aqueles que não emigraram, uma vez que a saúde mental deste foi abalada pelo afastamento dos vínculos relacionais, sentimento de abandono e falta de suporte emocional.

\subsection{Juventude e imigração familiar}

Tendo em vista os desafios inerentes ao processo migratório para todos os membros familiares, torna-se ainda mais custoso quando este se processa no ciclo de vida familiar adolescente. Em vista disso, as pesquisas de Vargas (2009), Qin (2008) e Aksel et al. (2007) apontam características peculiares à dinâmica familiar de adolescentes imigrantes, rede de apoio social dos jovens, bem como a autossatisfação destes a partir da imigração e o sentimento de bemestar subjetivo em um novo contexto sociocultural. Na pesquisa de Aksel et al. (2007), delimitou-se a influência da migração involuntária entre adolescentes que se deslocaram com as famílias para locais culturalmente distintos da Turquia. Verificou-se que o fenômeno migratório promoveu um impacto considerável na frequência escolar dos adolescentes, na baixa autoestima e satisfação com a vida, em limitações nas redes de apoio social bem como na dependência dos pais para atividades cotidianas.

Identificou-se, também, no estudo de Qin (2008), demais repercussões na dinâmica familiar com filhos adolescentes, como conflitos na comunicação, regras e limites e anseio por "liberdade" dos jovens em um novo contexto de convivência. $\mathrm{O}$ choque entre culturas diferentes predispóe, em algumas vezes, a dificuldades na formação da identidade étnica, o que, por conseguinte, agravase na adolescência, uma vez que os sujeitos estão constituindo sua própria identidade pessoal.

Cabe salientar que, no estudo desenvolvido por Vargas (2009), considerou-se o fenômeno migratório como condizente a uma etapa vital em que o jovem sai do núcleo familiar e parte em busca das aspirações profissionais e de formação acadêmica. Desse modo, pontuam-se características de vínculo familiar, tipo de apoio recebido dos pais e as remessas que subsidiam os jovens a cursar a universidade. 


\subsection{Manutenção das tradições culturais e familiares de origem}

Outro aspecto recorrente da temática pesquisada diz respeito à vigilância em se preservar as tradições culturais e familiares relativas ao contexto de origem dos emigrados. Três pesquisas (Jardim, 2000; Lask, 2000; Freire, 1997) tiveram como destaque retratar essa condição mediante o processo migratório.

Os resultados da investigação de Freire (1997) referem-se à condição de famílias portuguesas que imigraram para o Canadá. Desse modo, além do projeto de vida idealizado e dos desafios de aculturação, os pais alarmam-se com o receio de que os filhos percam as "raízes" de origem. Nesse sentido, realizam-se estratégias de aprendizagem da língua materna, visitas à pátria, preservação dos costumes e a manutenção de uma residência em Portugal.

Corroboram esses resultados os achados de Lask (2000), que faz reflexões sobre a imigração brasileira no Japão, enfatizando que os pais sentem receio de que seus filhos se apeguem à cultura japonesa e não desejem retornar ao Brasil. Assim, tendo em vista o desejo de retorno dos cônjuges ao Brasil, estes nem sempre colocam seus filhos na escola, pois temem que eles se esqueçam da língua materna e se, porventura, retornarem ao país de origem, não encontrem dificuldades de adaptação e comunicação. Por isso, há dificuldades de socialização das crianças brasileiras no Japão, pois estas acabam não compreendendo a língua japonesa, tampouco experienciam vivências brasileiras. Esse fato repercute no descompasso entre identidades biculturais no sistema familiar.

Associam-se a esse discurso os resultados obtidos pelo estudo de Jardim (2000), que mostram uma constante estratégia familiar que se pauta em preservar os costumes judaicos dos filhos, especialmente no que se refere aos valores culturais, religiosos e transmissóes intergeracionais, mediante ritos e costumes familiares.

\subsection{Imigração e projeto de vida familiar}

Pela análise dos artigos, essa categoria ilustrou, de modo contundente, a imigração como projeto de vida familiar, com base na idealização de melhorias na qualidade de vida mediante a ascensão profissional bem como outras aspirações pessoais por parte dos imigrantes.

Desse modo, os trabalhos de Puerta e Masdéu (2010), Ryan (2008) e Estrada (1982) discutem diferentes finalidades com as quais coube a decisão das famílias de emigrarem. Os dois primeiros estudos relacionam o papel da mulher no contexto migratório, sendo que, no primeiro artigo, os autores discutem sobre o projeto de vida de mulheres latino-americanas se deslocarem para a Espanha, com o intuito de se casarem e constituírem uma família; enquanto que, nos 
resultados de Ryan (2008), as mulheres enfermeiras da Irlanda são as pioneiras entre suas famílias a imigrarem para a Grã-Bretanha. Já no estudo de Estrada (1982), focam-se as dimensões profissionais como motivo preponderante entre os médicos colombianos para imigrarem aos Estados Unidos. Associam-se a esses estudos discussões em torno dos papéis de gênero nas migrações bem como do processo de aculturação entre as famílias pesquisadas.

\section{DISCUSSÃO}

De acordo com a análise das obras consultadas, é possível constatar um recente interesse pelo tema, haja vista as produçôes que tiveram maiores publicações nos últimos 13 anos. Tal apontamento confirma o que Paiva (2012) afirma acerca da lacuna nas produções científicas da Psicologia intercultural desde meados dos anos 1980 até os primeiros anos da década de 2000, no que tange aos estudos sobre migração e adaptação cultural. No entanto, cabe salientar que tal revisão pautou-se somente na busca em três idiomas, o que não caracteriza, de modo mais abrangente, demais publicações, especialmente em língua francesa, cujas produções ocupam espaço relevante nos estudos internacionais (Ferreira, 2012).

No que se refere às características dos participantes, prevaleceram famílias imigrantes de diferentes origens para diversos países de destino bem como jovens imigrantes. As idades não foram uniformes, apresentando variações, e tal heterogeneidade apresenta conformidade com os resultados encontrados na revisão de literatura de Muhlen, Dewes e Leite (2010) acerca dos processos de estresse e aculturação em pessoas que mudam de país. Tais resultados parecem demonstrar que não há uma alusão precisa acerca dos sujeitos-alvo da pesquisa, desde que sejam pessoas que vivenciaram o processo migratório.

Em relação aos aspectos metodológicos, sobressaiu-se o enfoque de estudo pesquisa-empírica, todavia foram registrados alguns estudos etnográficos bem como documentais, relatos de experiência, ensaio teórico e estudo de caso. Tal variedade parece explicar a ênfase multidisciplinar e a pluralidade das áreas que compreendem o fenômeno em questão. Por conseguinte, constatou-se a inexistência de revisões bibliográficas acerca da relação entre o fenômeno migratório e a dinâmica familiar. Diante disso, é considerável refletir ao que Echer (2001) propõe acerca da importância da elaboração de revisões de literatura. Para a autora, revisar o conteúdo existente em base de dados científicos permite encontrar as lacunas presentes e avançar o conhecimento, de modo a verificar as produçóes atuais e contribuir para possíveis intervenções propostas.

No que tange ao tipo de estudo, apenas 6 foram pesquisas longitudinais, enquanto que 18 artigos não deixaram claro qual tipo de delineamento foi 
empregado. Aquelas pesquisas caracterizadas como longitudinais analisaram o processo de aculturação das famílias e imigrantes em um novo contexto de vida. De acordo com Garmezy e Rutter (1983), os estudos longitudinais com curta duração são oportunos para investigar os padrões positivos ou negativos de adaptação de acontecimentos de vida específicos.

Em relação ao método, obtém-se com maior frequência o levantamento de dados, seguido do levantamento de dados/observação. No tocante às técnicas recorrentes, listam-se primeiramente a entrevista, seguida do questionário, observação/entrevista e registro de dados. Posteriormente, há os seguintes arranjos:

a) entrevista/observação;

b) entrevista/mapa de redes;

c) entrevista/grupo focal;

d) entrevista/genograma;

e) entrevista/escala;

f) questionário/escala;

g) observação/entrevista/questionário;

h) observação/entrevista/registro de dados.

Entre alguns instrumentos citados, é oportuno considerar a utilização do genograma e mapa de redes, especialmente em estudos que dimensionem o aspecto familiar bem como na compreensão das redes sociais dos membros familiares. Segundo Moré e Crepaldi (2012), o mapa de rede, como instrumento de coleta de dados, soma-se a outros já reconhecidos no campo da investigação qualitativa, tais como o genograma, auxiliando o pesquisador na busca de uma expressão mais aprofundada em torno de eventos vitais de um indivíduo e família.

Tendo em vista o significado e a interpretação que se tece com base nos fenômenos migratórios entre as famílias, especialmente no que tange aos afetos inerentes da cultura de origem dos indivíduos e ao processo de adaptação na sociedade majoritária, justifica-se a maior ocorrência pela análise de dados qualitativos na revisão realizada. Todavia também emergiram análises quantitativas, particularmente na comparação entre fenômenos culturais e aplicação de escalas que avaliaram o bem-estar subjetivo dos imigrantes. Nesse sentido, compreende-se que a realização de estudos multimétodos para avaliar os fenômenos migratórios parecem adequados dependendo do objetivo do estudo. 
Conforme Sampieri, Collado e Lucio (2013), o método misto de pesquisa, ou multimétodo, possibilita uma perspectiva mais ampla e profunda do fenômeno, tornando-o integral, holístico e completo. Este apresenta como finalidade o enriquecimento e a variabilidade dos dados, além de dimensionar uma análise integrativa e sistemática entre os métodos quantitativos e qualitativos.

Em síntese, os estudos consultados enfatizaram, em grande parte, o processo de aculturação e as dificuldades de adaptação das famílias migrantes, bem como o afastamento entre membros familiares, quando apenas um dos cônjuges emigra, deixando os filhos por diversos motivos, mas principalmente por melhores condições de vida e ascensão profissional. Todavia não foi amplamente discutido nas obras encontradas como se estabelecem os papéis familiares a partir do processo migratório, inclusive quando os pais emigram deixando os filhos sob os cuidados de parentes ou pessoas próximas. Também não foi encontradas entre os estudos vivências quanto ao processo de aculturação de retorno, bem como sobre a comum inversão dos papéis familiares entre pais e filhos, especialmente quando estes se mantêm na função de apresentar uma nova cultura aos pais, uma vez que, repetidas vezes, detêm maior facilidade com o novo idioma.

Embora muitos estudos tenham se referido aos processos de aculturação, particularmente apontando os desafios inerentes à condição dos sujeitos, bem como aos conflitos desencadeados, seria oportuno que os pesquisadores detectassem as respostas de enfrentamento que essas famílias ou sujeitos desenvolveram para lidar com as circunstâncias adversas que presenciaram. Outra observação pauta-se em considerar as redes de apoio que os imigrantes mencionam ter e mapear tais redes significativas que encontram em um novo contexto sociocultural, de modo a obter-se uma visão mais ampla e coerente do processo.

Cabe ressaltar que são diversas as perspectivas teóricas e discussões que norteiam o fenômeno das imigrações na atualidade, tais como o processo de aculturação e as implicaçôes decorrentes na dinâmica e no ciclo vital familiar dos membros migrantes. Entende-se, aqui, que o olhar intercultural amplia os fenômenos do estresse aculturativo e as dificuldades inerentes da aculturação, mas busca também compreender a influência dos fatores culturais no desenvolvimento e nos comportamentos dos migrantes de modo global e integrativo.

\section{CONSIDERAÇÕES FINAIS}

Este artigo apresentou como finalidade propor uma análise da produção científica sobre a relação entre o processo migratório e a dinâmica familiar de imigrantes. Para tanto, delineou-se uma análise sistemática quanto aos aspectos 
metodológicos encontrados nas obras consultadas, identificando as principais características e contribuições da literatura acerca da temática.

Verificaram-se lacunas existentes em relação à produção científica relacionada estritamente ao tema pesquisado, uma vez que os diversos resultados encontrados nas bases de dados privilegiam dimensões mais singulares do sujeito diante do fenômeno migratório, como os processos de aculturação e de saúde mental. Por conseguinte, foram excluídos da análise. Todavia é possível constatar um recente interesse pelas associações entre imigração e relações familiares, haja vista as produções que tiveram maiores publicações nos últimos 13 anos. Diante disso, sugere-se o avanço para os próximos estudos na área.

Identifica-se a relevância de novas revisões bibliográficas concernentes ao tema, contudo com estratégias diferentes de busca nos descritores e em demais bancos de dados, a fim de verificar se constam de tendências semelhantes. Outrossim, poderiam ser realizadas revisóes de literatura anteriores ao período estabelecido neste estudo, ou seja, uma análise histórica vinculada ao tema. Sugere-se ainda a revisão bibliográfica em demais idiomas, não se restringindo somente aos que foram consultados neste estudo.

No tocante aos desafios encontrados, torna-se difícil observar o fenômeno migratório sem considerar os processos familiares inerentes aos sujeitos pesquisados, como também não atentando às redes significativas e sociais em que estes estão inseridos. Diante disso, propóe-se o incremento de pesquisas que considerem tais aspectos, especialmente no panorama nacional e no campo psicológico, cujas produções parecem ser principiantes. Tal cenário também alude às práticas de intervenção que acolham essa demanda em prol da implementação de ações educativas de saúde e comunitárias para as famílias que vivenciam o processo da migração. 


\section{REFERÊNCIAS}

Aksel, S., Giin, Z., Irmak, T. Y. \& Cengelci, B. (2007). Migration and psychological status of adolescents in turkey. Journal of Adolescence, 42(167), 589-602.

Antonucci. T. C. \& Israel, B. A. (1986). Verticality of social support: a comparison of principal and network members' responses. Journal of Consulting and Clinical Psychology, 54, 432-37.

Bagno, S. (2007). A formação da identidade e das redes sociais na família de imigrantes italianos no Brasil. Pensando Famílias, 11(2),101-122.

Berry, J. W. (2004). Migração, aculturação e adaptação. In S. D. DeBiaggi \& G. J. Paiva (Orgs.), Psicologia, elimigração e cultura. (pp 29-46). São Paulo: Casa do Psicólogo.

Carter, B. \& McGoldrick, M. (1995). Etnicidade e o ciclo de vida familiar. In B. Carter \& M. McGoldrick, As mudanças no ciclo de vida familiar: uma estrutura para a terapia familiar. (pp. 65-82). Porto Alegre: Artmed.

Cerveny, C. M. O. (2002). Pensando a família sistemicamente. In C. M. O. Cerveny \& C. M. E. Berthoud (Eds.), Visitando a família ao longo do ciclo vital (vol. 3, p. 15-28). São Paulo: Casa do Psicólogo.

Dantas, S. D. (2012). Saúde mental e interculturalidade: implicações e novas proposições diante dos desafios em tempos de globalização. In S. D. Dantas (Org.), Diálogos interculturais: reflexōes interdisciplinares e intervençōes psicossociais. (pp. 109-160). São Paulo: Instituto de Estudos Avançados da Universidade de São Paulo.

Dantas, S. D., Ueno, L., Leifert, G. \& Suguiura, M. (2010). Identidade, migrações e dimensões psicossociais. Revista Internacional Mobilidade Humana, 34, 45-60.

Deepak, A. C. (2005). Parenting and the process of migration: possibilities within South Asian families. Columbia University School of Social Work, 84(5), 585-606.

Diener, E., Emmons, R., Larsen, J. \& Griffin, S. (1985). The satisfaction with life scale. Journal of Personality Assessment, 49, 71-75. 
Echer, I. C. (2001). A revisão de literatura e na construção do trabalho científico. Revista Gaúcha de Enfermagem, 22(2), 5-20.

Engebrigtsen, A. I. (2007). Kinship, gender and adaptation processes in exile: the case of Tamil and Somali families in Norway. Journal of Ethnic and Migration Studies, 33(5), 727-746.

Estrada, T. (1982). Migracion profesional y dislocacion familiar. Acta Médica Colombiana, 7(2), 51-59.

Ferreira, L. F. (2012). De minha língua a outra: migração literária e diálogo intercultural na obra autobiográfica de Vasilis Alexakis (Atenas, 1943). In S. D. Dantas (Org.), Diálogos interculturais: reflexōes interdisciplinares e intervençôes psicossociais. (pp. 109-160). São Paulo: Instituto de Estudos Avançados da Universidade de São Paulo.

Freire, J. (1997). Emigração e independência: o caso português no Quebec. Sociologias: Problemas e Práticas, (23), 9-35.

Garmezy, N., Rutter, M. (1983). Stress, coping, and development in children. New York: McGraw-Hill.

Hope, J. (2011). New insights into family learning for refugees: bonding, bridging and building transcultural capital. Literacy, 45(2), 91-97.

Jardim, D. F. (2000). Diásporas, viagens e alteridades: as experiências familiares dos palestinos no extremo Sul do Brasil. Horizontes Antropológicos, 6(14), 3969.

Lask, T. (2000). Imigração brasileira no Japão: o mito da volta e a preservação da identidade. Horizontes Antropológicos, 6(14), 71-92.

Machado, C. S. (1997). A família e o impacto da imigração (Curitiba, 18541991). Revista Brasileira de História, 17(34), 75-100. Recuperado a partir de https://dx.doi.org/10.1590/S0102-01881997000200004

Martins-Borges, L. (2013). Migração involuntária como fator de risco à saúde mental. Remhu - Revista Interdisciplinar da Mobilidade Humana, 21(40), 151162.

Mercer, M. C. M. (2012). Those easily forgotten: the impact of emigration on those left behind. Family Process, 51(3), 376-390. 
Minuchin, S. (1982). Famílias: funcionamento \& tratamento. Porto Alegre: Artes Médicas.

Moré, C. L. O. O. \& Crepaldi, M. A. (2012). O mapa de rede social significativa como instrumento de investigação no contexto da pesquisa qualitativa. Novas Perspectivas Sistêmicas, 21(43), 84-98.

Morrison, M. \& James, S. (2009). Portuguese immigrant families: the impact of acculturation. Family Process, 48(1), 151-166.

Mulhen, B. K. V., Dewes, D. \& Leite, J. C. C. (2010). Stress e processo de adaptação em pessoas que mudam de país: uma revisão de literatura. Ciência em movimento, 12(24), 59-68.

Paiva, G. J. (2012). A perspectiva intercultural: aspectos filosóficos e históricos. In S. D. Dantas (Org.), Diálogos interculturais: reflexões interdisciplinares e intervençôes psicossociais. (pp. 207-218). São Paulo: Instituto de Estudos Avançados da Universidade de São Paulo.

Puerta Y. B. \& Masdéu, M. S. (2010). Parejas en el espacio transnacional: los proyectos de mujeres que emigran por motivos conyugales. Migraciones Internacionales, 5(3), 143-174.

Qin, D. B. (2008). Doing well vs. feeling well: understanding family dynamics and the psychological adjustment of Chinese immigrant adolescents. Journal of Youth and Adolescence, 37(1), 22-35.

Queiroz, A. H. (2008). Migração familiar: da quebra à reconstrução das redes sociais significativas. (Dissertação de Mestrado), Universidade Federal de Santa Catarina Programa de Pós-graduação em Psicologia, Florianópolis.

Rosenberg, M. (1965). Society and the adolescent self-image. Princeton: Princeton University Press.

Ryan, L. (2008). I had a sister in England': family-led migration, social networks and Irish nurses. Journal of Ethnic and Migration Studies, 34(3), 453-470.

Ryan, L., Sales, R., Tilki, M. \& Siara, B. (2009). Family strategies and transnational migration: recent Polish migrants in London. Journal of Ethnic and Migration Studies, 35(1), 61-77.

Sampieri, R. H., Collado, C. F. \& Lucio, M. P. B. (2013). Metodologia de pesquisa. Porto Alegre: Penso. 
Sarriera, J. C., Pizzinato, A. \& Meneses, M. P. R. (2005). Aspectos psicossociais da imigração familiar na Grande Porto Alegre. Estudos de Psicologia, 10(1), $5-13$.

Schmidt, B., Crepaldi, M. A., Vieira, M. L. \& Moré, C. L. O. O. (2011). Relacionamento conjugal e temperamento de crianças: uma revisão de literatura. Arquivos Brasileiros de Psicologia, 63(3), 89-106.

Sluzki, C. E. (1997). A rede social na prática sistêmica. São Paulo: Casa do Psicólogo.

Soto, C. D. (2012). La migración internacional paterna o materna una lectura desde los sujetos jóvenes. Revista Latinoamericana de Ciencias Sociales, Niñez y Juventud, 10(1), 611-624.

Vargas, R. (2009). Características del fenómeno migratorio internaciona en estudiantes de la Universidad Libre de Pereira. Cultura del Cuidado Enfermería, 6(2), 5-13.

Vazsonyi, A. T., Castillo, E. T. \& Huang, L. (2006). Are developmental processes affected by immigration? Family Processes, internalizing behaviors, and externalizing behaviors. Journal of Youth and Adolescence, 35(5), 795-809.

Waters, J. L. (2002). Flexible families? "Astronaut" households and the experiences of lone mothers in Vancouver, British Columbia. Social \& Cultural Geography, 3 (2), 117-134.

Waters, J. L. (2011). Time and transnationalism: a longitudinal study of immigration, endurance and settlement in Canada. Journal of Ethnic and Migration Studies, 37(7), 1119-1135.

White, A., Laoire, C., Tyrrell, N. \& Méndez, F. C. (2011). Children's roles in transnational migration. Journal of Ethnic and Migration Studies, 37(8), 11591170 .

Ximena, C.T. (2005). Depresión en adolescentes hijos depadresmigrantes; estudiantes de octavo, noveno e décimo años de educación básica de los Colegios mixtos Jorge Icaza y del Instituto de Investigación, Educación y Promoción Popular del Ecuador (Inepe) del Sur Occidente de Quito. (Tese de Doutorado), Universidad Central del Ecuador, Facultad de Ciencias Médicas, Quito. 